
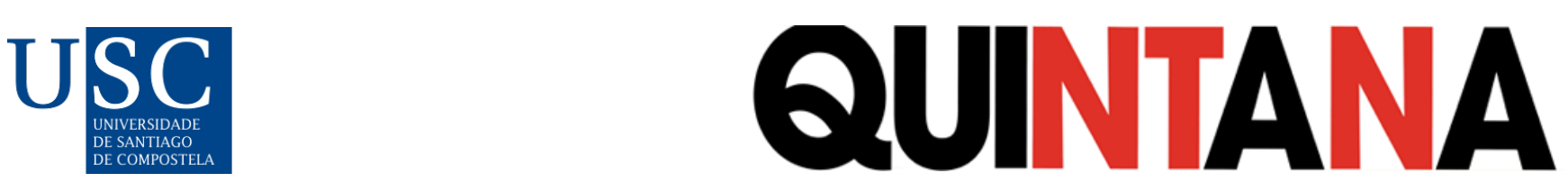

Quintana: revista do Departamento de Historia da Arte, (20), 2021. ISSN-e: 2340-0005

https://doi.org/10.15304/quintana.20.7472

Colaboracións

\title{
DA ARTE E DA TÉCNICA: OS DESENHOS COMO FONTE DE INFORMAÇÃO DA PRÁTICA ARTÍSTICA. A OFICINA DOS VALADIER, OURIVES ROMANOS DOS SÉCULOS XVIII E XIX
} ART AND TECHNIQUE: DRAWINGS AS A SOURCE OF INFORMATION ON ARTISTIC PRACTICE. THE VALADIER WORKSHOP, ROMAN GOLDSMITHS OF THE XVIII AND XIX CENTURIES

\author{
Teresa Leonor M. Vale iD \\ Universidade de Lisboa, Portugal \\ teresalmvale@campus.ul.pt
}

Recibido: 04/02/2021; Aceptado: 16/02/2021

\section{Resumo}

Do ponto de vista do historiador de arte, um desenho constitui-se normalmente como uma obra de arte objeto do seu estudo. No presente texto, contudo, propomo-nos sobretudo efetuar, para além de reconhecer a presença e o papel desempenhado pelo desenho no âmbito da oficina dos Valadier, ourives e fundidores romanos ativos nos séculos XVIII e XIX, uma aproximação a alguns desenhos na sua qualidade de fonte de informação relativamente a práticas e técnicas no contexto da oficina.

Palavras-chave: desenhos; ourives; fundidores; Valadier; Roma.

\begin{abstract}
From the point of view of the art historian, a drawing is normally a work of art that is the object of his study. In the present text, however, in addition to recognising the presence and role played by drawing in the workshop of the Valadier family, Roman goldsmiths and foundrymen working in the 18th and 19th centuries, we intend to look at some drawings as a source of information about practices and techniques in the workshop context.
\end{abstract}

Keywords: drawings; goldsmiths; founders; Valadier; Rome.

\section{OS VALADIER E A SUA OFICINA}

Mais do que empreender uma abordagem biográfica dos diversos elementos da família Valadier, que não teria sentido nesta sede, os parágrafos seguintes pretendem efectuar uma aproximação aos membros desta família de artistas centrada na oficina, procurando contribuir para um melhor conhecimento do seu funcionamento, bem como, se possível, da sua evolução ao longo do tempo. 
Não seria, contudo, adequado ignorar os agentes que ao longo de décadas moldaram o perfil dessa oficina, pelo que se apresentarão de seguida tão-só brevíssimas sínteses biográficas dos membros da família que tiveram a responsabilidade de orientar a oficina dos Valadier ou que a ela deram um contributo relevante.

Sem pretensões de trazer novidades, estas sínteses visam assim facultar apenas os elementos essenciais à compreensão da oficina, selecionando-se as informações tidas como relevantes entre as compiladas pelos diferentes autores que se ocuparam em biografar Andrea, Luigi e Giuseppe Valadier.

Entre esses autores o primeiro a elaborar esboços biográficos destes artistas foi Costantino Bulgari, na sua fundamental e incontornável obra em dois volumes: Argentieri, Gemmari e Orafi d'Italia, publicada em Roma em meados do século passado (Bulgari 1959, II, 494-496) e devidamente actualizada em 1987 por Anna Bulgari Calissoni (Bulgari Calissoni 1987, 427-429). Os informes essenciais sobre a vida dos artistas da família Valadier constavam já desses contributos, aos quais se juntaram, a partir da década de oitenta do século XX, os de um autor determinante para o conhecimento do tema em estudo, aquele que mais se ocupou dos Valadier ao longo de múltiplas publicações: Alvar González-Palacios (González-Palacios 1984, 1993, 1996, 1997, 2004, 2018). Com efeito, González-Palacios, durante décadas e até ao presente nunca deixou de aprofundar a sua investigação em torno dos Valadier, concedendo uma muito particular atenção à figura de Luigi Valadier.

Andrea Valadier (1695-1759) nasceu em Aramont, na Provença francesa, e daí viajou para Roma, onde sabemos que já residia no ano de 1714. Andrea aprendeu na cidade pontifícia a actividade de metalista e de ourives, tendo obtido a patente de ourives da prata a 27 de Maio de 1725 e possuindo por muitos anos oficina nas imediações da praça de S. Luigi dei Francesi, na proximidade da igreja nacional dos franceses. Na mesma cidade veio a falecer, a 23 de Julho de 1759, tendo sido sepultado na igreja de S. Dionigi alle Quattro Fontane, hoje inexistente, demolida que foi no século XX, por via de alterações urbanísticas da zona em que se situava.

Não são numerosas as obras de Andrea devidamente identificadas que chegaram até à actualidade. Algumas das peças ainda sobreviventes foram já realizadas em colaboração com seu filho Luigi Valadier. É o caso das grades destinadas ao baptistério da basílica patriarcal de Lisboa, realizadas por Andrea e Luigi, no seguimento de uma encomenda de D. João V (1706-1750).

Desaparecidas na sequência do terramoto de 1755, as grades, realizadas em bronze dourado na década de quarenta do século XVIII, chegaram de certa forma até nós através do desenho do denominado Álbum Weale

Desaparecidas na sequência do terramoto de 1755, as grandes, realizadas em bronze dourado na década de quarenta do século XVIII, chegaram de certa forma até nós através do desenho do denominado Álbum Weale ${ }^{1}$, e de outros três desenhos, nomeadamente de um constante do álbum da Pinacoteca de Faenza (Vale 2017) ${ }^{2}$, de outro integrante das colecções do Museu Nacional de Arte Antiga e ainda de um terceiro desenho, pertencente ao conjunto já denominado de Londres ${ }^{3}$. Das mesmas grades existiria, à data da morte de Andrea, um modelo, pois o mesmo surge referenciado no inventário de bens efectuado no seguimento do falecimento do ourives, a 6 de Outubro de 1759, que tivemos ocasião de publicar (Vale 2017).

Filho de Andrea, Luigi Valadier, nascido a 26 de Fevereiro de 1726, deu continuidade à actividade paterna, possuindo contudo formação no âmbito da arquitectura. Com efeito, Luigi venceu mesmo o segundo prémio da terceira classe do Concurso Clementino da Accademia di S. Luca do ano de 
1750 com o desenho de dois alçados da igreja de Santa Maria della Pace de Roma, o qual se conserva ainda nas colecções da academia romana (Marconi, Cipriani, Valeriani 1974).

Entre 1754 e 1756 Luigi Valadier terá efectuado uma viagem a Paris, eventualmente com a finalidade de aí aperfeiçoar os seus conhecimentos no domínio da ourivesaria, mas acerca de tal deslocação à nação dos seus antepassados subsiste o desconhecimento. De regresso à cidade pontifícia, Luigi casou, em 1756, com Caterina della Valle (filha do escultor florentino activo em Roma Filippo della Valle), tendo o casal tido vários filhos, entre eles Maria Clementina e Giuseppe $^{4}$, ambos figurados com sua mãe, cerca de 1766, num retrato da autoria de Giuseppe Bottani (1717-1784), que se conserva no Museo di Roma ${ }^{1}$.

Após a morte do pai, ocorrida em 1759, como se disse, Luigi Valadier obteve a confirmação da patente de ourives (24 de Fevereiro de 1760) e desenvolveu a sua actividade contando com a colaboração de seu irmão Giovanni, separando-se os irmãos em 1762. Luigi passou então a residir, com a mulher e os filhos, na strada Paolina (actual via del Babuino), na casa que fazia esquina com o vicolo del Carciofolo (Di Castro 2006). Note-se que naquela artéria e suas imediatas vizinhanças se localizavam então diversas oficinas de artistas, dos escultores aos pintores, passando pelos ourives, facto que terá pesado na opção de Luigi Valadier em se fixar numa zona diferente da de S. Luigi dei Francesi, onde a família sempre vivera e trabalhara desde a chegada do pai Andrea à cidade pontifícia.

Luigi angaria para a sua oficina uma prestigiada clientela: desde logo constituída pelo Papa e pela aristocracia romana, mas também por aquela francesa, inglesa e espanhola. Entre os clientes portugueses conta-se o embaixador de Portugal em Roma, o 3ํ Marquês de Louriçal, D. Henrique de Meneses (1727-1787) para quem Valadier realizou um surtout de table em 1784, como noticia a Gazzetta Universale (Gazzetta Universale 1784, 394).

Contudo, e apesar das prestigiosas encomendas, a saúde financeira da oficina não seria a melhor, pois em 1780 Luigi Valadier viu-se obrigado a aceitar a figura de um sócio. Provavelmente associada a estes problemas financeiros encontra-se a morte de Luigi, que a 15 de Setembro de 1785 se suicidou no rio Tibre (Chracas 1785, 3).

Giuseppe Valadier (1762-1839) era filho de Luigi Valadier e de Caterina della Valle e distinguiuse sobretudo como arquitecto, tendo legado, como é sabido, obra relevante à cidade de Roma. Logo em 1775, com 13 anos de idade, Giuseppe Valadier ganhou o primeiro prémio da segunda classe do Concurso Clementino com um desenho para um altar e aos 19 anos, em 1781, foi nomeado arquitecto dos Sacri Palazzi (Sacros Palácios Apostólicos). Cargo a que se seguiu, em 1786, o de Architetto Camerale (da Reverenda Câmara Apostólica).

Logo no ano imediato ao falecimento do pai, Giuseppe surge indicado como ourives estabelecido na casa que fazia esquina da via del Babuino com o vicolo del Carciofolo.

Giuseppe Valadier, desenvolvendo sempre a partir da década de noventa, uma actividade dominantemente de arquitecto, não descura, contudo, o funcionamento da oficina de ourives, mantendo sempre em dia os pagamentos devidos à congregação dos ourives romanos. Tal circunstância, e apesar dos diferendos, terá permitido a continuação da laboração, pelo menos no âmbito dos metais não preciosos e da fundição. Deste modo pôde prosseguir a actividade de uma oficina próspera que continuava a receber e a satisfazer encomendas.

A implementação do Tratado de Tolentino (1797), para além das suas devastadoras consequências no âmbito da ourivesaria da cidade de Roma, determinou que fosse Giuseppe Valadier o responsável pela embalagem das obras de arte italianas destinadas a ser enviadas para 
França. Tarefa decerto amarga, para um artista que, ainda que de origem francesa, era e se sentiria decerto plenamente romano, pertencendo à segunda geração nascida na cidade pontifícia.

No ano de 1827 Giuseppe vendia o que surge designado então como o seu "negozio di belle arti" - denotando esta designação o carácter comercial da actividade desenvolvida -, sito na via del Babuino, no 89, aos ourives e metalistas Giuseppe (1765-1839) e Pietro Paolo Spagna (1793-1861), vindo a falecer no dia 1 de Fevereiro de 1839.

\section{A OFICINA E OS DESENHOS À LUZ DOS DOCUMENTOS}

São essencialmente três os documentos que nos permitem conhecer a evolução da oficina familiar dos Valadier. 0 primeiro é o inventário datado de 6 de Outubro de $1759^{5}$, efectuado no seguimento do falecimento de Andrea, o segundo aquele redigido após a morte de Luigi, com data de 30 de Setembro de $1785^{6}$, e o terceiro o manuscrito conhecido como o Registro, elaborado em $1810^{7}$, quando Giuseppe considerava a hipótese de vender o negócio familiar.

0 inventário de 1759, constante dos fundos notariais do Archivio di Stato di Roma, revela em parte o recheio da casa e aquele da oficina, que Luigi Valadier passaria a dirigir após a morte do pai. O manuscrito faculta informações relevantes quanto ao(s) espaço(s), à presença de instrumentos de trabalho e materiais, de desenhos, de modelos e de objectos. Quanto aos espaços, é a casa a primeira a ser referida, sita sobre a oficina, que ocupava o piso térreo do edifício da via del Pozzo delle Cornacchie. Curiosamente, é no contexto do espaço residencial que nos é dado localizar a única referência a desenhos. Com efeito, é aí que se encontra "un comodino di Legno di Portogallo con un tiratore a sopra coperchio da aprire con data sopra la Vernice con dentro diuersi disegni della professione di Argentiere, con saratura e chiaue" ${ }^{8}$.

A oficina constava de dois espaços distintos, um primeiro simplesmente designado como oficina, e que corresponderia ao compartimento principal consagrado à actividade desenvolvida (nas suas múltiplas vertentes), e um segundo espaço, podemos depreender que de menores dimensões, visto que é identificado como "pequena sala": "stanziola contigua alla detta Bottega dove è la vasca", destinado à lavagem e / arrefecimento. Do ponto de vista da sua estruturação e organização, a oficina legada por Andrea a seu filho Luigi afigurava-se bastante simples.

A oficina de Luigi era bem mais complexa e plurifuncional, como aliás bem revelam o inventário de 1785 e outras fontes documentais. Quanto aos desenhos, enquanto no tempo de Andrea estes eram conservados em casa, na oficina de Luigi os desenhos faziam parte de um espaço que podemos considerar como uma verdadeira biblioteca, constituída por uma rica colecção de livros e de estampas. Com efeito, um pequeno conjunto, reunido sob o título de "Varj Disegni e carte inutili" no inventário de $1785^{10}$, estava fechado no interior de uma pequena credência no "stanziolino, o sia studio dove lavorava il medesimo Defunto Cavaliere" ${ }^{11}$, um espaço exclusivamente reservado a Luigi, no qual o artista podia dedicar-se ao desenho e, sobretudo, ocupar-se da gestão e da administração da oficina. 
Fig. 1. Oficina Valadier, desenho para um relicário-ostensório. Sanguínea, tinta e aguada de castanho. $673 \times 380$ $\mathrm{mm}$.

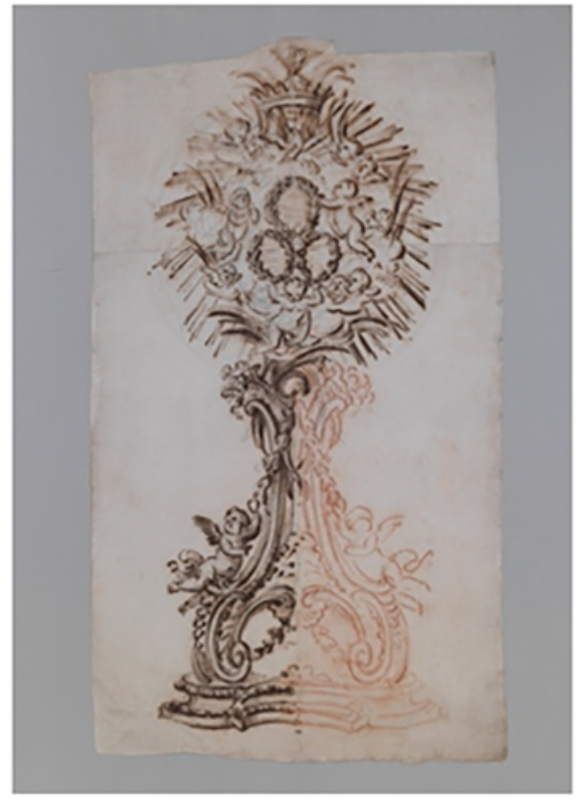

Fig. 2. Oficina Valadier, desenho para uma píxide. Lápis, tinta castanha, aguada de cinzento e castanho. $280 \mathrm{x}$ $219 \mathrm{~mm}$.

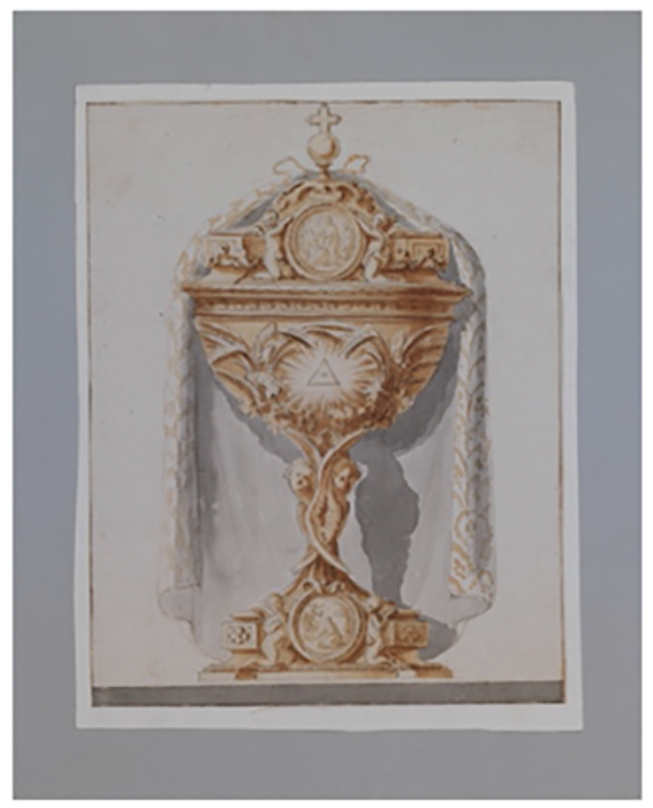


Fig. 3. Oficina Valadier, desenho para um galheteiro. Grafite, pena, tinta castanha e cinzenta. $230 \times 285 \mathrm{~mm}$. Antichità Alberto Di Castro, Roma.

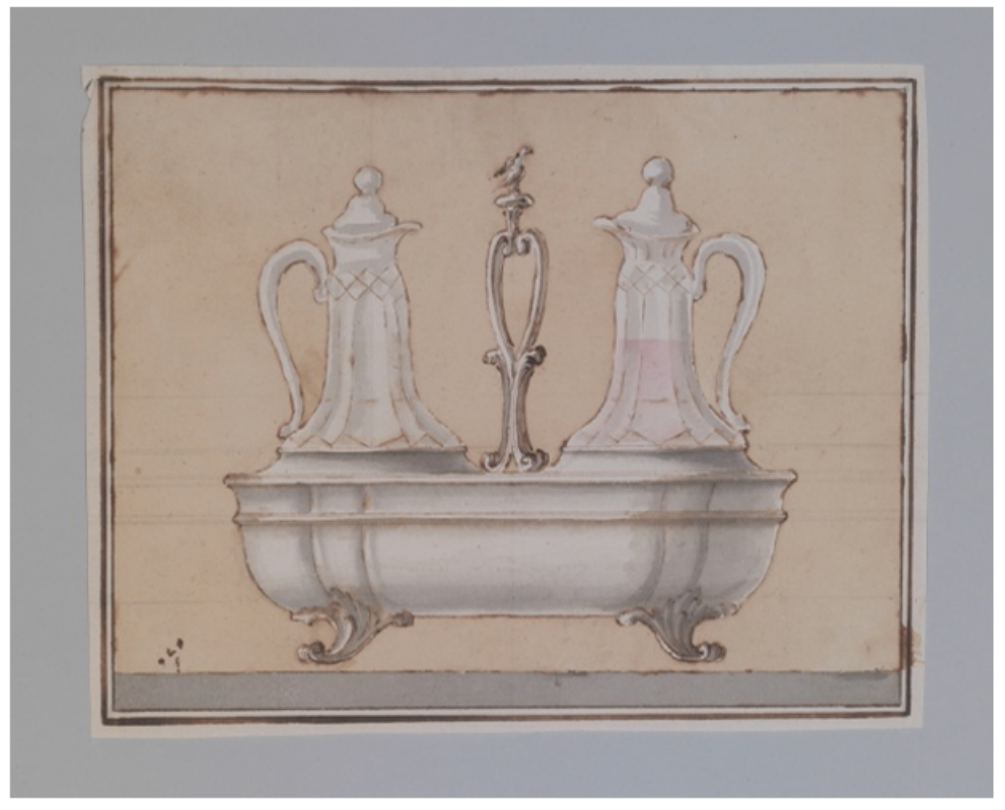

A oficina de Giuseppe organizava-se em múltiplos espaços, sendo alguns claramente diferenciados pela especificidade da funcionalidade que lhes era atribuída. No início de Oitocentos a oficina Valadier (localizada no edifício hoje detentor do no 89 da via del Babuino, como de disse) possuía, como nos revela o Registro, um total de dezoito compartimentos, sendo os primeiros dois, dando sobre a via pública (podendo depreender-se que em concreto sobre a strada Paolina, actual via del Babuino) para a qual abriam portas, janelas e montras, destinados ao trabalho oficinal, mas também destinados à recepção de visitantes (veja-se clientes) e exibição de peças. Os seguintes dez compartimentos - organizados em torno de dois pátios - eram plenamente consagrados ao trabalho, sendo dois deles especificamente de fundição. Os restantes 6 compartimentos constituíam-se como espaços de apoio e arrumo.

Segundo as informações proporcionadas pelo Registro de 1810, aos desenhos era consagrado um compartimento específico, o primeiro, dando sobre a strada Paolina, onde se podiam reconhecer diversas tipologias de desenhos organizados no interior de credências. Com a expressão "diversi contorni di disegni per comodo di chi deve lavorare" indicam-se muito provavelmente desenhos de carácter operativo ${ }^{12}$ (Fig. 1) tendo ao lado, sobre a mesma credência, e é interessante notálo, um tinteiro (un "calamaio e polverino di ottone"13), pronto a ser usado. Na primeira gaveta de uma segunda credência conservava-se outro tipo de desenhos, aqueles tidos como de qualidade adequada a serem visionados pelos eventuais clientes ("sonovi diversi dei migliori disegni"14) (Fig. 2 e Fig. 3). Uma terceira e última secção de desenhos, em estreita relação com a anterior, era constituída pelo que pode designar-se desenhos de apresentação, ou seja, aqueles que mostram a versão definitiva da obra e que tinham como objectivo permitir ao cliente a visualização com precisão (e consequente compreensão) do aspecto final da obra (Fig. 4). 
Fig. 4. Luigi Valadier (1726-1785), atrib., desenho para o refrescador do serviço Borghese. Pena e tinta castanha, aguada de cinzento e castanho. 581 x 441 mm. Antichità Alberto Di Castro, Roma.

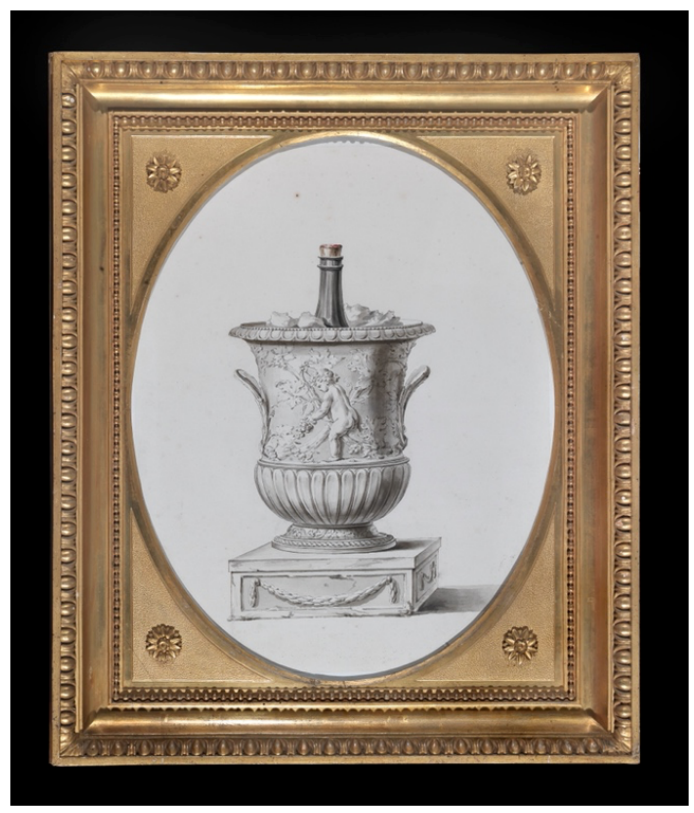

\section{OS DESENHOS COMO FONTE DE INFORMAÇÃO}

O desenho da peça correspondia ao primeiro estágio de fixação da ideia e dos requisitos eventualmente estabelecidos pelo encomendador. Quanto à autoria do(s) desenho(s) que servia(m) de base à realização da obra, ela poderia pertencer ao próprio ourives, a um outro ourives ou ainda a um outro artista, escultor, pintor ou mesmo arquitecto. 0 desenho, com vista à realização de uma peça de ourivesaria poderia também ser facultado pelo encomendador - ainda que naturalmente não fosse este o seu autor (salvaguardadas as devidas excepções) -, feito esse "a suo gusto" ou "a suo genio", expressões coevas com frequência utilizadas, que traduzem o claro envolvimento do encomendador na ideia e concepção da obra (Montagu 2007, 56).

A primeira situação acima enunciada, aquela em que o ourives era o autor dos desenhos que seguiam para a produção da obra, era a mais frequente. Os desenhos dos ourives, como bem assinala Peter Fuhring são dos menos conhecidos no universo do desenho e constituem-se como um grupo um pouco marginal, todavia "Cada folha- para além do seu interesse puramente estético - constituise como um ponto de partida para que o historiador possa compreender o papel do desenho na elaboração do projecto de ourivesaria, da sua concepção à sua execução. A partir do momento em que compreendemos que o ourives pode ser um notável desenhador e que possui a capacidade de esculpir os seus próprios modelos tridimensionais, afigura-se lógico que dos seus desenhos transpareça o interesse pela escultura." (Fuhring 2008, 49 tradução nossa) ${ }^{15}$.

Os desenhos produzidos por ourives no contexto das suas oficinas apresentavam assim características específicas (Fuhring 2008, 53-54), que traduziam as necessidades dos seus autores com vista à subsequente concretização material da peça. Todavia, os desenhos de carácter projectual - que poderiam ir do mero registo de uma ideia para uma forma ou uma solução decorativa (Fig. 5) até peças desenhadas de considerável elaboração (Fig. 6) - não eram os únicos 
passíveis de serem produzidos e reconhecidos no interior das oficinas de Setecentos, pelo que importa referir a existência de desenhos de apresentação, a que já atrás se aludiu.

Fig. 5. Oficina Valadier, estudo para plinto ou base. Lápis e tinta castanha. 270 × 347 mm. Antichità Alberto Di Castro, Roma.

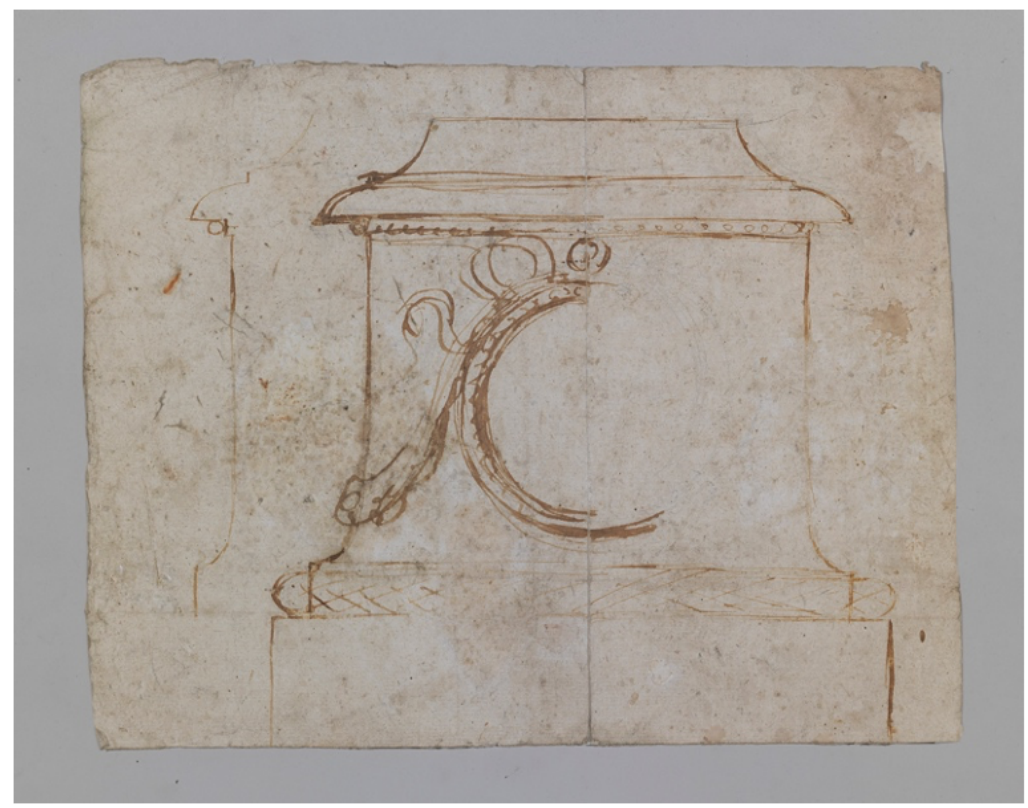

Fig. 6. Oficina Valadier, desenho para uma terrina e prato. Grafite, pena, tinta e aguada de castanho. $340 \times 236$ $\mathrm{mm}$. Colecção privada.

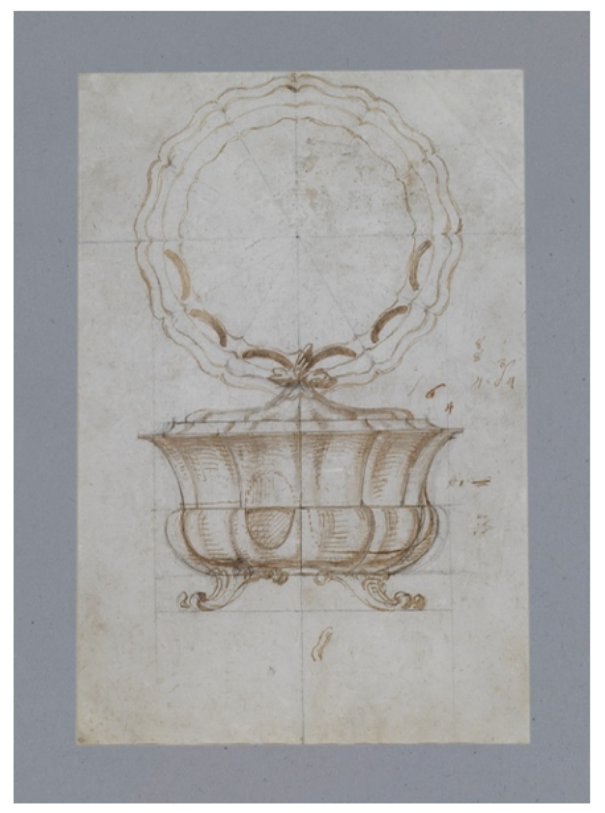

Muito diferentes, do ponto de vista da sua funcionalidade e, consequentemente, quanto ao aspecto final, em relação aos desenhos projectuais, estes outros destinavam-se a apresentar a peça ao encomendador. Seguindo ainda o elucidativo discurso de Fuhring: "No primeiro caso a procura 
da forma definitiva não se encontra ainda concluída e, frequentemente, reconhecemos no desenho variantes quanto ao contorno ou quanto a pormenores. (...) a partir do momento que a forma final está definida, o ourives pode então conceder particular atenção à execução do desenho e ao seu acabamento. $O$ que se assumia como importante era a obtenção de uma apresentação clara que facultasse ao encomendador ou ao cliente o maior número de informações possível." (Fuhring 2008, 55 tradução nossa) ${ }^{16}$.

Enquanto os primeiros permaneciam geralmente na oficina, os segundos poderiam ser deslocados para a residência do encomendador, facto que, associado ao carácter por vezes descartável dos desenhos projectuais, explica a mais frequente sobrevivência dos desenhos de apresentação. Por outro lado, o carácter acabado destes últimos contribuiu para a sua valorização e apreço por parte de coleccionadores a partir do século XIX, o que ulteriormente contribuiu para a sua preservação.

Um outro aspecto que merece menção, ainda quanto às questões relacionadas com o desenho no âmbito da concepção e concretização da obra de ourivesaria barroca italiana é a circunstância da utilização de um mesmo desenho por mais de um ourives, mesmo para além do contexto oficinal, onde laboram diversos profissionais. Com efeito, diferentes ourives poderem seguir um mesmo desenho, como as peças sobreviventes bem atestam. É esse o caso de Antonio Gigli (c. 1704-1761?) e Leandro Gagliardi (1729-1804) no que à realização da naveta e turíbulo da capela de S. João Baptista da igreja de S. Roque de Lisboa diz respeito. Antonio Gigli começou por realizar a naveta e o turíbulo que faziam parte do denominado "serviço para a missa", mas, tendo as duas peças sido oferecidas, por vontade do rei D. João V de Portugal ao papa Bento XIV (que depois as ofertou à catedral de $\mathrm{S}$. Pedro da sua cidade natal de Bolonha, em cujo Tesouro na actualidade podem ser admiradas), o ourives Leandro Gagliardi executou outra naveta e outro turíbulo, baseados nos mesmos desenhos e em tudo idênticos aos de Gigli. Assim, embora possam reconhecer-se diferenças relativas à qualidade técnica, que se reflectem na plasticidade das peças, as mesmas afiguram-se na generalidade idênticas (Vale 2015, 199-247, Vale 2017, 77-103).

Outro exemplo, talvez ainda mais elucidativo, é o dos trinta castiçais de prata dourada, destinados à Exposição do Santíssimo na mesma capela régia de Lisboa, os quais foram realizados por um conjunto de seis diferentes ourives, seguindo um mesmo desenho da autoria de Giovanni Felice Sanini (1727-1787) (Montagu 2007, 18-25).

Ainda no âmbito dos desenhos devem referir-se aqueles que reproduzem obras de arte já existentes que passam a constituir-se como referentes para novas peças a realizar. É esse o caso de diversas esculturas em prata que reproduzem, decerto a partir da realização de desenhos (seguidos da elaboração de modelos, naturalmente), estátuas por vezes de muito maiores dimensões e realizadas em diferentes materiais. A título de exemplo refiram-se os apóstolos em bronze dourado realizados por Leandro Gagliardi (para o cardeal Chigi em 1776), os quais se baseiam naqueles monumentais e marmóreos da basílica de S. João de Latrão (González-Palacios 2000, 184-185). Também, e no âmbito da oficina que mais nos importa, merece referência o $S$. Pedro, de Luigi Valadier, realizado em bronze dourado para o altar da catedral de Monreale, que se baseia a estátua do mesmo apóstolo da autoria de Pierre Etienne Monnot (1657-1733), a qual integra o já mencionado apostolado lateranense.

Finalmente, importará referir a flexibilidade reconhecível no processo ainda quanto ao papel do desenho, como fica bem claro no discurso de Jennifer Montagu, no qual se reflecte igualmente sobre a questão da autoria das peças: "Assistimos a Giardini incorporando nas suas obras relevos 
elaborados a partir de pinturas de outros artistas, a Barchi trabalhando a partir de desenhos de Luzi e a Gagliardi a partir de modelos do escultor Giovanni Battista Maini. Há muitos modos de realizar obras de prata detentoras de um carácter escultórico e existem muitas formas de colaboração entre o ourives e aqueles que lhe fornecem os desenhos ou os modelos, tal como entre o principale (designação do responsável pela oficina) e aqueles que trabalhavam sob as suas ordens. É assim adequado afirmar que essas obras foram realizadas por Giardini, Barchi ou Gagliardi? Claro que sim, mas acontece que estou bem mais interessada em compreender as complexas relações entre os vários elementos efectivamente intervenientes na produção dessas maravilhosas obras de arte." (Montagu 2000, $25^{17}$, tradução nossa; Vitali 2007, 67-79).

Centremos agora a nossa atenção numa abordagem dos desenhos enquanto fonte de informação da prática artística no contexto da oficina dos Valadier.

0 estudo que directamente efectuámos de mais de três centenas de desenhos pertencentes à oficina familiar dos Valadier, com vista à sua publicação, bem como a observação de inúmeros outros desenhos com a mesma origem, constantes de acervos públicos (nomeadamente da Pinacoteca de Faenza, do Museo Napoleonico de Roma, do Victoria \& Albert Museum de Londres), e ainda de exemplares que vêm surgindo no mercado de antiquariato, permitiu-nos não apenas identificar obras a eles correspondentes (Vale 2019, 60-67, 252-256, 258-261), mas reflectir sobre o seu carácter e a sua funcionalidade. Um aspecto que se assume como particularmente interessante, do nosso ponto de vista, é a compreensão das modalidades de utilização de tais desenhos e do que os mesmos nos podem revelar das técnicas e das práticas no contexto oficinal.

Seguidamente abordaremos três tipos de desenhos que configuram duas diferentes situações: o uso múltiplo (um mesmo desenho é utilizado para a feitura de múltiplas obras) e o uso único. Para a primeira situação consideraremos os desenhos perfurados e os desenhos de componentes, enquanto que para a segunda abordaremos os desenhos com anotações.

Fig. 7. Oficina Valadier, desenho para moldura oval. Lápis, tinta e aguada de castanho. $365 \times 270$ mm. Antichità Alberto Di Castro, Roma.

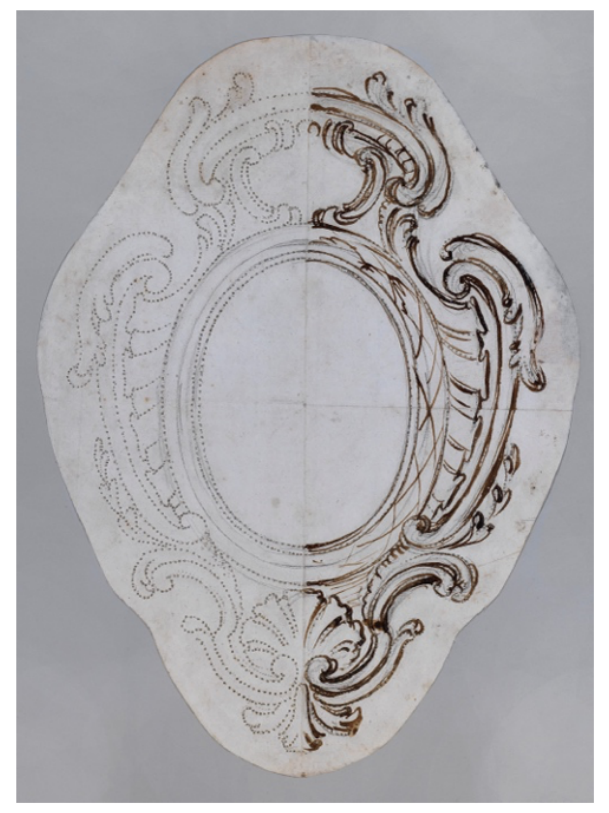


Comecemos pelos desenhos perfurados, cuja sobrevivência é particularmente rara devido à deterioração causada pelo sucessivo manuseamento dos mesmos no contexto da oficina. Tratase de uma tipologia específica na qual os contornos das formas representadas são perfurados, de molde a que possam depois, colocados sobre o metal, e por meio de um ponteiro permitir a marcação da superfície. Efectua-se assim a passagem do desenho em papel para o metal, trabalhando-se seguidamente este tendo o puncionado como guia. As formas do objecto são assim determinadas de modo simples, por meio de uma transposição directa do desenho (Fig. 7). Estes desenhos são com frequência parciais, isto é, correspondem a partes da peça, devendo recorrer-se a vários desenhos que, articulados entre si, permitem a realização do todo.

É igualmente muito interessante que em alguns destes desenhos se observem ainda as marcas dos pontos de fixação sobre o metal (Fig. 8), por forma a que se não verificassem desvios na transposição do desenho.

Os desenhos de componentes, frequentemente de motivos decorativos, mas por vezes também de soluções formais recorrentes, são reconhecíveis com relativa abundância no contexto do conjunto por nós estudado, sendo por vezes relativamente fácil identificar a sua utilização em peças sobreviventes (Fig. 9), sobretudo naquelas integrantes de tipologias mais frequentemente realizadas (relicários, molduras, etc.).

Fig. 8. Oficina Valadier, desenhos para partes de sacras. Lápis e tinta castanha. $480 \times 520 \mathrm{~mm}$ e $300 \times 410 \mathrm{~mm}$, respectivamente. Antichità Alberto Di Castro, Roma.
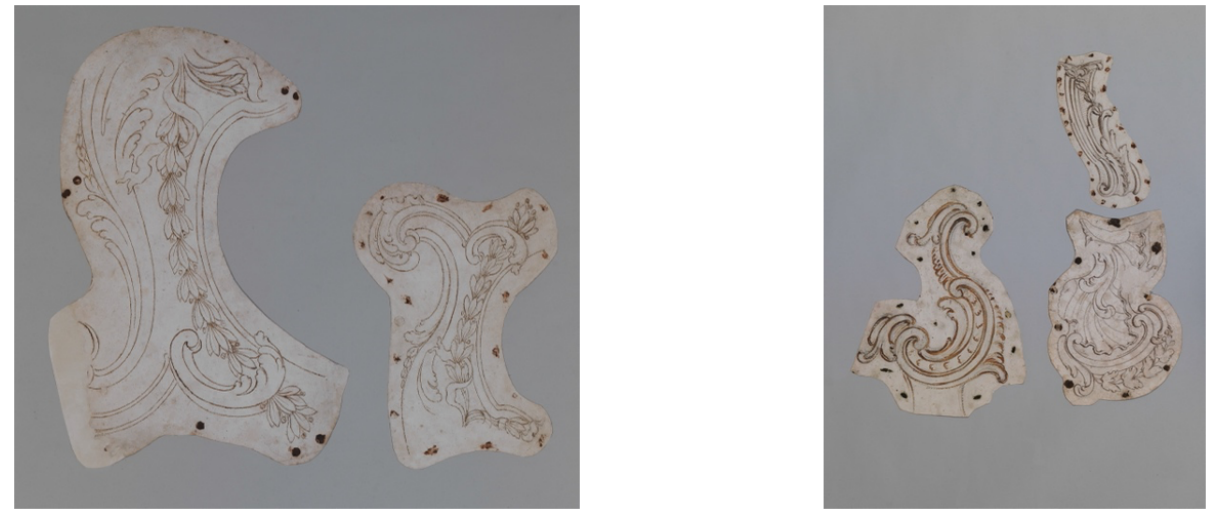
Fig. 9. Oficina Valadier, desenhos para partes de sacras. Lápis e tinta castanha. 470 × $195 \mathrm{~mm}$ e 200 × $350 \mathrm{~mm}$, respectivamente. Antichità Alberto Di Castro, Roma.
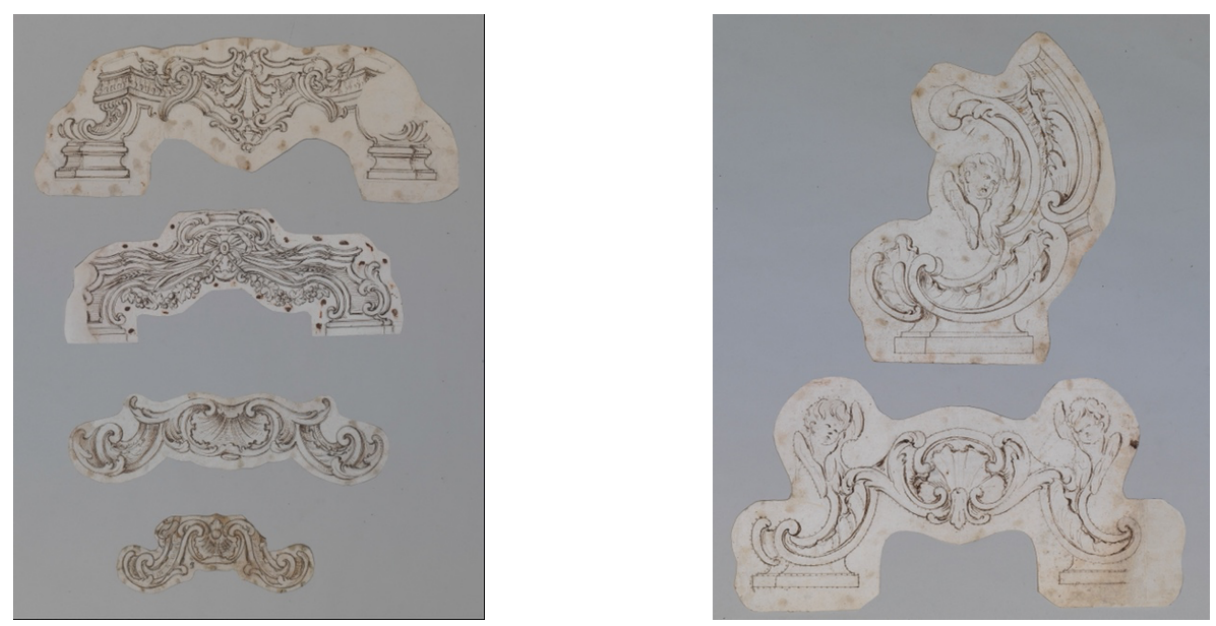

Já os desenhos com anotações configuram, como se referiu, uma situação diversa e constituemse como que um exercício de individualização, de personalização, do desenho e, sobretudo, do objecto para cuja concretização concorrem. Assim, incorporando o desenho propriamente dito, identificam-se componentes de texto que podem ser anotações básicas quanto a cores ou a materiais - como a identificação das pedras preciosas a incorporar nas mitras cujos desenhos se apresentam (Fig. 10) - mas que, por vezes, se assumem como mais extensas (indicações específicas para recurso a determinadas soluções técnicas), com o objectivo de possibilitar a compreensão da intenção do autor por parte de interlocutores, como seriam desde logo os profissionais activos no contexto da oficina.

Finalmente, afigura-se-nos pertinente referir um último aspecto, que concerne a relação com o cliente e que se traduz na elaboração de um mesmo desenho apresentando mais do que uma solução, compositiva ou decorativa. Desta situação dão testemunho diversos desenhos realizados no âmbito da oficina dos Valadier, sendo particularmente bons exemplos o de quatro propostas para duas molduras (Fig. 11) e aquele de duas propostas para uma trembleuse (Fig. 12). Este último, orgulhosamente assinado "Luigi Valadier argentiere a S. Luigi dei Francesi” (Luigi Valadier, ourives junto a S. Luís dos Franceses), fornece assim uma ulterior informação importante: uma aproximação à data da sua feitura. Com efeito, ainda que não datado, o desenho em questão revela por meio desta simples inscrição no canto inferior esquerdo, feita pela mão do seu autor, que o mesmo seria anterior a 1762, data em que Luigi Valadier abandona o conforto da zona tradicionalmente ocupada pela comunidade de francesa da Urbe e, assumindo a sua romanidade e procurando novos desafios, desloca a sua oficina para a strada Paolina, na qual, alguns anos volvidos, viria a receber a visita do Sumo Pontífice, de soberanos e inúmeros aristocratas europeus, que constituiriam a sua nutrida e ilustre clientela. 
Fig. 10. Oficina Valadier (Carlo Sartori, atrib.), desenhos para mitras, c. 1780. Lápis e tinta castanha. 584 × 445 mm, 584 x 440 mm e 584 × 440 mm, respetivamente. Antichità Alberto Di Castro, Roma.
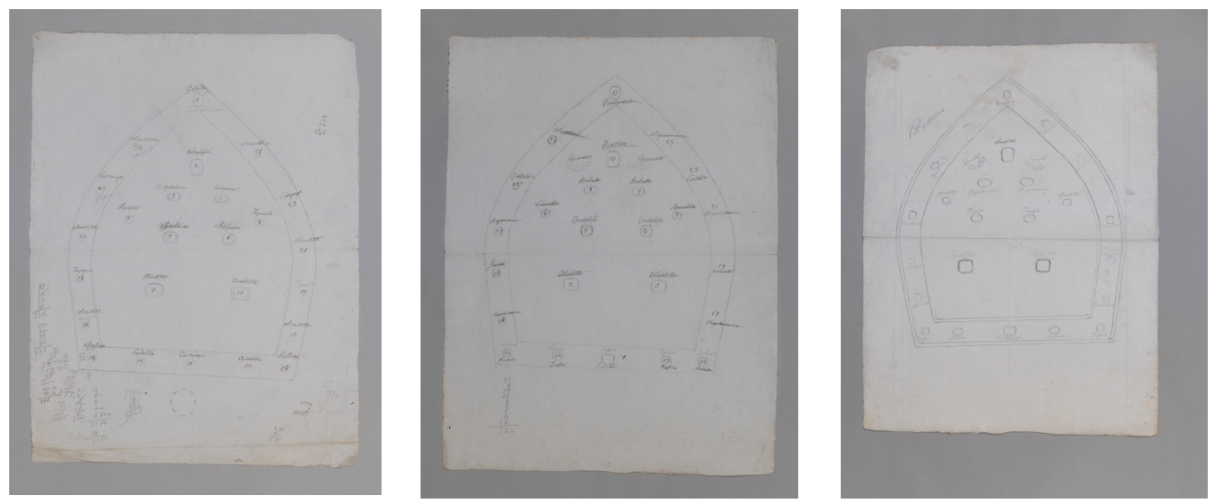

Fig. 11. Oficina Valadier, desenhos para molduras. Pena e tinta castanha. 178 × 242 mm. Antichità Alberto Di Castro, Roma. Fig. 12. Luigi Valadier (1726-1785), atrib., desenho para uma trembleuse, Luigi Valadier, antes de 1762. Grafite, pena, tinta e aguada de castanho. $336 \times 239 \mathrm{~mm}$. Colecção privada.
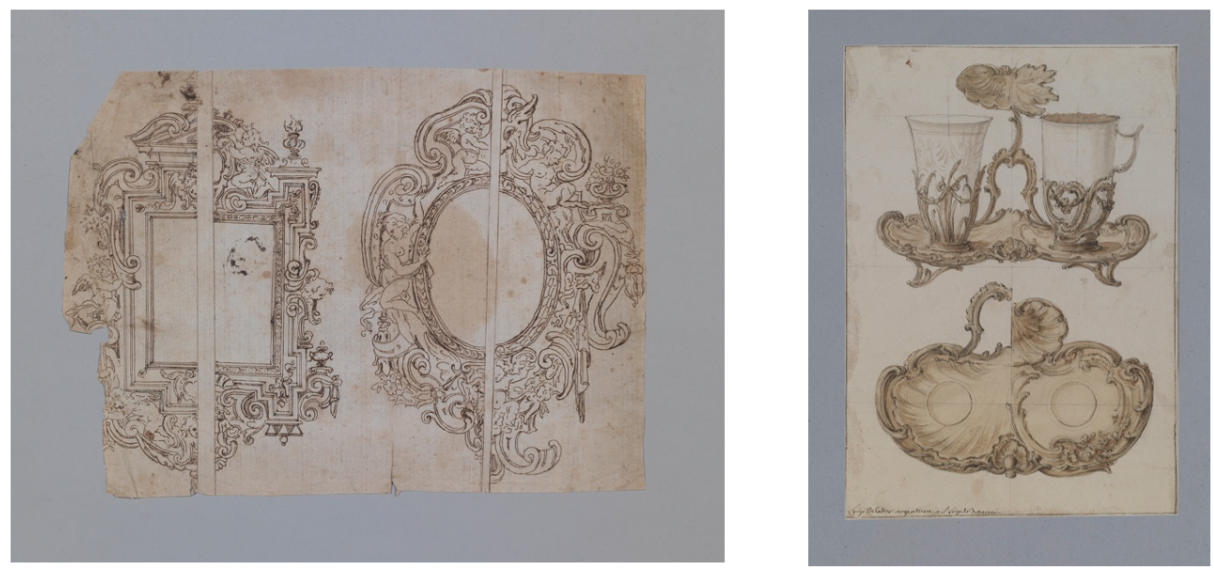

\section{Fontes manuscritas}

Archivio di Stato di Roma, 30 Not. Uff. 17, busta 386, fls. 451-491

Archivio di Stato di Roma, 30 Not. Cap., Uff. 30, notaio Monti Silvestro, c. 290, c. 292

Frick Art Reference Library, Nova Iorque, Registro Generale di tutti li Lavori Ferriordegni e d'altri generi necessari per le professioni di argentiere, doratore, e fonditore di qualunque genere varie pietre dure $e$ tenere lavorate e grezze nel negozio del Signore Giuseppe Valadier nell'anno MDCCCX / Inventory of all the works, tools, utensils and other articles necessary for the profession of silversmith, gilder, and caster of every sort, various stones, hard and soft, cut and uncut, in the shop of Signor Giuseppe valadier in the year MDCCCX

\section{Estudos}

Bulgari, Constantino. Argentieri, Gemmari e Orafi d'Italia. Vol. II. Roma: Lorenzo del Turco, 1958-1959. 
Bulgari Calissoni, Anna. Argentieri, Gemmari e Orafi di Roma. Roma: Fratelli Palombi Editori, 1987.

Chracas, Luca Antonio. Diario Ordinario 1120, 24 de Setembro de 1785.

Di Castro, Francesca. Via Margutta. Cinquecento anni di storia e d'arte. Roma: Edizioni Kappa, 2006.

Fuhring, Peter. "Dessins d'orfèvres-sculpteurs au XVIIIe siècle." In Dessins de Sculpteurs I. Troisièmes Rencontres Internationales du Salon du Dessin, ed. G. SCHERF, 49-60. Paris, 2008.

Gazzetta Universale 51, 10 de Dezembro de 1784.

González-Palacios, Alvar. Arredi e Ornamenti alla Corte di Roma 1560-1795. Milão: Electa, 2004.

González-Palacios, Alvar. "Di alcuni vasi di Luigi Valadier." Bollettino dei Musei Comunalidi Roma X (1996): 121-129.

González-Palacios, Alvar. Il Gusto dei Principi. Arte di Corte del XVII e del XVIII Secolo. Vol. II. Milão: Longanesi, 1993.

González-Palacios, Alvar. Il Tempio del Gusto. Le Arti Decorative in Italia fra Classicismi e Barocco. Roma e il Regno delle Due Sicilie, Vol. II. Milão: Longanesi, 1984.

González-Palacios, Alvar. Luigi Valadier. Nova Iorque: The Frick Collection, 2018.

González-Palacios, Alvar. I Valadier.L'Album dei Disegni del Museo Napoleonico, Roma: Palombi Editori, 2015.

González-Palacios, Alvar (dir.). L'Oro di Valadier: Un Genio nella Roma del Settecento. Roma: Fratelli Palombi Editori, 1997.

Leone, Francesco. "Album Valadier della Pinacoteca Comunale di Faenza. Catalogo dei Disegni." In Valadier. Splendore nella Roma del Settecento, ed. Geraldine Leardi, 81-183. Milão: Officina Libraria, 2019.

Mandroux-França, Marie Thérèse. "Rome, Lisbonne, Rio de Janeiro, Londres et Paris: Le Long Voyage du Recueil Weale, 1745-1995.” Colóquio. Artes, 2a Série, 109 (1996): 5-22.

Marconi, P., Angela Cipriani, EnricoValeriani. I Disegni di Architettura dell'Accademia di S. Luca. Roma: Quasar, 1974.

Montagu, Jennifer. "I modelli degli argentieri”. In Ori e Argenti. Capolavori del '700 da Arrighi a Valadier, ed. Gabriele Barucca e Jennifer Montagu, 53-61. MIlano: Skira, 2007.

Montagu, Jennifer. "The Practice of Roman Baroque Silver Sculpture." The Silver Society Journal 12 (2000): $18-25$

Susino, S., "190. Giuseppe Bottani, Caterina della Valle Valadier with her Children Giuseppe e Maria Clementina." In Art in Rome in the Eighteenth Century, ed. E.P. Borown, J. J. Rishel, 335-336. Philadelphia: Merrel, 2000

Teolato, Chiara. "Limpresa di Luigi Valadier. Produzione di piccole e grandi sculture in bronzo nell'inventario del 1785 e nel Catalogo della Lotteria del 1792." Studi di Storia dell'Arte 29 (2018): 211-231.

Vale, Teresa Leonor M. "A Ourivesaria. Do carácter único da coleção de ourivesaria da Capela de S. João Batista." In A Capela de São João Batista da Igreja de São Roque. A Encomenda, a obra, as coleções, ed. Teresa Leonor M. Vale, 221-247. Lisboa: Imprensa Nacional-Casa da Moeda, 2015

Vale, Teresa Leonor M. "Presenza e Ruolo del Disegno nella Bottega Valadier”, “26. Busto reliquiario di san Bernardino da Siena. Disegno per il busto reliquiario di san Bernardino da Siena”, "28. Reliquiario del velo della Vergine. Disegno per la parte superiore di un reliquiario a ostensorio. Disegno per la parte superiore di un reliquiario a ostensorio. Disegno per la base di un reliquiario". In In Valadier. Splendore nella Roma del Settecento, ed. Geraldine Leardi, 60-67, 252-255, 258-261. Milano: Officina Libraria, 2019.

Vale, Teresa Leonor M. "Analbum with a chapel inside it. The chapel of St. John the Baptist in the Libro degli Abozzi." In From Rome to Lisbon. An album for the Magnanimous King, ed. Teresa Leonor M. Vale, 77-103. Lisboa: Scribe, 2015. 
Vale, Teresa Leonor M. (ed.). From Rome to Lisbon. An album for the Magnanimous King. Lisboa: Scribe, 2015.

Vale, Teresa Leonor M. (ed.). The Art of the Valadiers. Torino: Umberto Allemandi \& Co., 2017.

Vitali, Aldo. "Note tecniche sugli argenti romani del Settecento." In Ori e Argenti. Capolavori del '700 da Arrighi a Valadier, ed. Gabriele Barucca e Jennifer Montagu, 67-79. Milano: Skira, 2007.

Notas

1 Óleo sobre tela, $72 \mathrm{~cm}$ (alt.) x $60 \mathrm{~cm}$ (larg.), inv. MR1011.

1 O denominado Álbum Weale (designação advinda do nome do editor inglês John Weale em cuja posse esteve) é composto por 160 folhas numeradas (recto e verso) de 1 a 319 e consiste no minucioso registo, escrito e desenhado, das encomendas de obras de arte italianas destinadas a Lisboa (designadamente à Patriarcal e à capela de S. João Baptista), assim reunido sob o título de Libro degli Abozzi de Disegni delle Commissioni che si fanno in Roma per Ordine della Corte. O volume em questão, após vicissitudes várias, que fizeram mesmo equacionar uma sua eventual destruição (perfeitamente narradas por Mandroux-França 1996, 5-22), consta na actualidade dos fundos da Biblioteca da École Nationale Supérieure des Beaux-Arts de Paris (Ms. 497), onde ingressou pela doação do arquitecto Joseph-Michel Lesoufaché, em 1889; foi entretanto publicado como Vale 2015.

2 A totalidade dos desenhos do álbum de Faenza foi entretanto publicada por Leone 2019, 81-184.

3 Todos publicados em VALE 2017, 70-71.

4 Stefano Susino revela a existência de outros filhos que terão perecido na infância remetendo para documentação do Archivio del Vicariato de Roma (S. Lorenzo in Lucina, Census de 1769) - Susino 2000, 335-336.

5 Archivio di Stato di Roma (A.S.R.), 30 Not. Cap. Uff. 17, busta 386, fls. 451-491, publ. por VALE, 2017, 103-123.

6 A.S.R., 30 Not. Cap., Uff. 30, notaio Monti Silvestro, parcialmente publ. por Teolato 2018, 211-231.

7 Frick Art Reference Library, Nova Iorque (F.A.R.L.), Registro Generale di tutti li Lavori Ferriordegni e d'altri generi necessari per le professioni di argentiere, doratore, e fonditore di qualunque genere varie pietre dure $e$ tenere lavorate e grezze nel negozio del Signore Giuseppe Valadier nell'anno MDCCCX / Inventory of all the works, tools, utensils and other articles necessary for the profession of silversmith, gilder, and caster of every sort, various stones, hard and soft, cut and uncut, in the shop of Signor Giuseppe valadier in the year MDCCCX, publ. por VALE 2017, 125-253.

8 A.S.R., 30 Not. Cap. Uff. 17, busta 386, fol. 461-461v.

9 A.S.R., 30 Not. Cap. Uff. 17, busta 386, fol. 471.

10 A.S.R., 30 Not. Cap., Uff. 30, notaio Monti Silvestro, C. 292.

11 A.S.R, 30 Not. Cap., Uff. 30, notaio Monti Silvestro, c. 290.

12 F.A.R.L., Registro..., p. 16.

13 F.A.R.L., Registro..., p. 16.

14 F.A.R.L., Registro..., p. 27.

15 "Chaque feuille constitue - en dehors de son intérêt purement esthétique - un point de départ pour l'historien pour comprendre le rôle du dessin dans l'élaboration du projet d'orfèvrerie, de sa conception à son exécution. Dès que nous comprenons que l'orfèvre peut être un dessinateur remarquable et qu'il doit être capable de sculpter pour réaliser ses propres modèles en trois dimensions, il paraît logique que l'intérêt pour la sculpture se traduise dans ses dessins.".

16 "Dans le premier cas, la recherche de la forme définitive n'est pas terminée et souvent on voit dans le dessin des variantes pour le contour et les détails. (...). Dès que la forme définitive était arrêtée, l'orfèvre pouvait donner une attention particulière à l'exécution du dessin et à sa finition. Ce qui comptait, c'était d'obtenir une présentation claire qui donne le plus de renseignements possible au commanditaire ou au client.".

17 "We have seen Giardini combining his own designs with reliefs taken from the paintings of others, Barchi working from a drawing by Luzi, and Gagliardi working from models by the sculptor Maini. There were many different ways of making sculptural silver and there was room for the many forms of collaboration between the silversmith and those who provided the designs or the models, just as between the principale (as the head of a workshop was called) and those who worked under him. Are we therefore justified in stating that these works 
were "by" Giardini, Barchi or Gagliardi? Of course we are; but I happen to be more interested in the complicated relationships between the numerous men actually involved in producing these marvelous works of art.". 